\title{
PROUST NO CAMINHO DO MAL: \\ O DESVIO DA ESCRITA
}

PROUST ON THE EVIL WAY:

THE DEVIANCE OF WRITING

\section{Francisco Renato de Souza}

\author{
Universidade Federal do Rio de Janeiro \\ Rio de Janeiro - Brasil
}

\begin{abstract}
Based on a reading of the book Literature and Evil by the philosopher Georges Bataille, this article analyzes the notion of Evil present in Marcel Proust's novel In Search of Lost Time, taking as the basis the narrator's (un)satisfied relationship with his beloved Albertine, and also the notion of deviation established by the narrator regarding certain characters' homosexuality. From (un)satisfaction and sexual deviance, Proust's work may have some aspects in common with Bataille's Evil, as for him these topics also become the basis of a narrative structure which, through discursive movement, moves away increasingly from the space of Good, which would become the space of satisfaction, standard behavior and objectivity. In Search of Lost Time is thus configured as the space of error, of ambiguity, of deviation - the space of Evil.
\end{abstract}

Keywords: Marcel Proust, deviance, homosexuality, evil, Georges Bataille.

\section{Résumé}

Cet article examine, à partir de la lecture du livre La littérature et le mal, du philosophe Georges Bataille, la notion du Mal présente dans l'œuvre $\grave{A}$ la recherche du temps perdu, de l'écrivain Marcel Proust, s'appuyant sur la relation (in)satisfaite du narrateur avec sa bienaimée Albertine et le concept de déviance établi par le narrateur proustien à travers l'homosexualité de certains personnages. De par l'(In)satisfaction et la déviance sexuelle, l'œuvre proustienne se rapproche du Mal bataillien quand elle confere à ces thèmes la base de sa structure narrative et, par le mouvement discursif, s'éloigne de plus en plus de l'espace du Bien, qui serait alors l'espace de la satisfaction, de

\section{Resumo}

Este artigo analisa, a partir da leitura do livro A literatura e o mal, do filósofo Georges Bataille, a ideia do Mal presente na obra Em busca do tempo perdido, do escritor Marcel Proust, tomando como base a relaçáo (in)satisfeita do narrador com sua amada Albertine e a noção de desvio estabelecida pelo narrador proustiano em relação à homossexualidade de determinados personagens. Da (in)satisfação e do desvio sexual, a obra proustiana se aproxima do Mal bataillano ao conferir a esses temas a base de sua estrutura narrativa e, pelo movimento discursivo, se afastar cada vez mais do espaço do Bem, que viria a ser o espaço da satisfação, da conduta padrão, 
la conduite normale, de l'objectivité. La Recherche constitue l'espace de l'erreur, de l'ambiguïté, de la déviance - espace du Mal.

Mots-clés: Marcel Proust, déviance, homosexualité, mal, Georges Bataille. da objetividade. A Busca se configura como o espaço do erro, da ambiguidade, do desvio - espaço do Mal.

Palavras-chave: Marcel Proust, desvio, homossexualidade, mal, Georges Bataille.

No decorrer da obra Em busca do tempo perdido, do escritor Marcel Proust, as reviravoltas da relação amorosa do narrador com sua amada, Albertine, acompanham a inconstância de um sentimento desenvolvido a partir da ambivalência de um desejo que se constitui menos pelo valor do objeto almejado do que pelo objetivo de se apoderar dele pela posse. Dessa forma, a ameaça da impossibilidade da posse é o fator que reacende o desejo do narrador por Albertine, cada vez que este arrefece pela seguridade de sua conquista. A ameaça, sofrimento que atormenta o narrador e póe em constante oscilação o seu amor pela companheira, se apresenta na obra proustiana pelo zelo excessivo do ciúme. Triunfar sobre os demais concorrentes de Albertine e mantê-la como um troféu são as duas etapas que asseguram ao narrador a conquista do seu amor: "E no entanto para mim, amar carnalmente significava triunfar sobre numerosos concorrentes. Nunca será demais repetir, era mais que tudo um alívio." (PROUST, 2011, p. 90). Aproximando-se de uma disputa, mais do que de uma relação amorosa, esse jogo tem como impedimento maior de uma vitória certa o possível desejo carnal de Albertine por mulheres. A esse desejo, o narrador atribui um valor de vício. Esse vício, o narrador classifica como Mal. Portanto, mais do que o Amor, o que prevalece nessa relação amorosa é o Mal.

Assim, desde $\grave{A}$ sombra das raparigas em flor, segundo livro da obra Em busca do tempo perdido, no qual o narrador, em sua primeira temporada em Balbec, se encanta pela jovial garota ainda desconhecida, até o sexto livro, A fugitiva, quando o narrador tem conhecimento da morte da entáo excompanheira, a oscilação do seu amor é permeada pela dúvida intermitente em relação às tendências homossexuais de Albertine. A relação se faz, portanto, através de suposições, elucubrações, deduções: "Quantas hipóteses possíveis! Possíveis somente. Eu construía táo bem a verdade, mas no plano do possível somente" (PROUST, 2012, p. 28). A verdade construída mentalmente por ele em relação à amada se desenvolve no decorrer do que podemos classificar de três fases. Inicialmente, a da projeção, quando a imagem que obsedava o narrador era a de uma jovial ciclista de boina misturada entre as outras 
raparigas do grupinho de Balbec, uma tela em branco que ele preenchia com as múltiplas possibilidades que o desconhecido permite à imaginação, colorindo e valorizando o objeto que ele entáo deseja ardentemente possuir. Objeto que, no entanto, se mostra cindido entre aquilo que realmente é e o seu invólucro idealizado pela imaginação, processo que inicia a forma dúbia pela qual o narrador veria a amada, continuamente indefinida entre a projeção e a realidade: "Em face da medíocre e tocante Albertine com quem eu tinha falado, eu via a misteriosa Albertine diante do mar. Eram agora lembranças, isto é, quadros, dos quais nenhum me parecia mais verdadeiro que o outro." (PROUST, 2006b, p. 531).

Em seguida, na fase da posse, o narrador mantém Albertine em cativeiro, morando consigo às escondidas em seu apartamento em Paris, apartada da sociedade e rigorosamente monitorada em seus passeios diários pela amiga Andrée e pelo motorista - fase que o póe em oscilação entre o interesse e o desinteresse no seu objeto de posse, que então tem o seu valor cotado pela iminência ou não da perda. Entre essas duas fases, nasce o traço da suspeita que então marcaria a posição ambígua do narrador em relação à amada: "Creio que mentiria se dissesse já haver começado a dolorosa e perpétua desconfiança que devia inspirar-me Albertine, e com mais forte razão o caráter peculiar, sobretudo gomorriano, de que se deveria revestir essa desconfiança." (PROUST, 2008, p. 226). Por fim, a fase da perda se dá a partir da fuga de Albertine do cativeiro, quando então o abandono reacende no narrador a necessidade vital de reavê-la, e o faz retornar ao estágio inicial, amando Albertine pela sua ausência, refazendo sua imagem em um jogo de contrastes que permeia o seu imaginário - no qual ora Albertine surge como inocente de qualquer suspeita homossexual, ora lhe é reafirmada a conduta do vício e da mentira que lhe é inerente. Fase que se desenvolve ainda através de um processo de luto pela perda do objeto, luto que passa a ser literal com a notícia da morte de Albertine.

A passagem de uma fase à outra será lida neste artigo pelo caminho que se faz da obra Sodoma e Gomorra à $A$ prisioneira, e desta à $A$ fugitiva. No elo dessa tríade do amor traçado pelo ciúme - que se constrói pelo jogo de dissimulação e mentira, reforçando o imaginário do narrador, ao mesmo tempo que reforça a sua narração, e por fim é marcada pela própria dissimulação e mentira que ele engendra no intuito de combatê-las - está a presença do Mal. E, como emblema do Mal, duas personagens figuram no imaginário apavorado do narrador, o casal lésbico composto pela Srta. Vinteuil e sua amante. Em Sodoma e Gomorra, na sua segunda estada em Balbec, o narrador promete à mãe pôr fim ao seu relacionamento com Albertine; porém a obra se encerra com uma comunicação inversa, a do filho que relata à mãe ser imprescindível o seu casamento com a companheira. Pois, na véspera de 
anunciar o rompimento à mulher da qual até a companhia o exasperava, o narrador escuta uma revelação distraída de Albertine, que lhe afirma ter vivido por um tempo em companhia da Srta.Vinteuil e da sua amante, consideradas por ela como duas irmãs mais velhas.

Perante tal revelação, o desprezo sentido por Albertine se reveste de afeição, pois o narrador deduz como consequência de uma ruptura o retorno da amada ao convívio com as amigas e, portanto, o seu desvio definitivo no caminho do vício, sobrepondo, na lembrança da cena lésbica marcante que observara na infância, a imagem de Albertine na da amante da Srta. Vinteuil:

Mas por detrás da praia de Balbec, do mar, do nascer do sol que mamáe mostrava, eu via, com movimentos de desespero que não lhe escapavam, o quarto de Montjouvain, onde Albertine, rósea, enroscada como uma grande gata, o nariz travesso, tinha tomado o lugar da amiga da srta.Vinteuil e dizia, com rompantes de seu riso voluptuoso: "Pois bem! Se nos virem, tanto melhor. Entấo eu não me animaria a cuspir naquele macaco velho?”. Era esta cena que eu via atrás da que se estendeu na janela e que não era, sobre a outra, mais que um véu pálido, superposto como um reflexo. Parecia, com efeito, quase irreal, como uma paisagem pintada. (PROUST, 2008, p. 604-5)

A sobreposiçáo de cenas personifica a teia que o narrador tece na composição de sua relaçáo amorosa. Aquilo que está diante dos seus olhos só pode ser visto pelo reflexo da cena rememorada, que é ainda transmutada em uma nova cena, a cena imaginativa, esta surgida como a representação "real" do medo que a inspirou. O horror ao vício que o narrador atribui aos homossexuais tem como cena primária aquela que observara na infância, na qual a filha cuja má conduta findara por levar o pai à morte goza, ainda vestindo o luto, do prazer carnal com a amante que cospe na fotografia do pai morto. É, portanto, pelo véu da desconfiança que o narrador forjará continuamente uma cena que coloque Albertine como uma desviada. Na sobreposição de cenas acima descrita, o narrador proustiano se mantém ainda de fora desta, na posição de observador, e Albertine se duplica como a lésbica que toma o lugar da amiga da Srta. Viteuil. Georges Bataille, em A literatura e o Mal, no capítulo intitulado "Proust", refaz esta cena, considerada pelo filósofo como a mais forte de a Busca, pela sobreposiçáo de cada personagem que dela participa, e a expande ao criar um paralelo entre os dois relacionamentos amorosos, no qual os pares Srta.Vinteuil/narrador e amante da Srta. Vinteuil/ Albertine são marcados pelo desvio, o Mal, e se opóem ao duplo Sr.Vinteuil/ mãe do narrador, a norma infligida, o Bem.

No paralelo estabelecido por Bataille para os dois casais de amantes, o desvio da norma caracteriza a proximidade destes com o Mal. Para a Srta. Vinteuil e a amante, este desvio se dá pela homossexualidade, vício do qual o 
narrador intenta distanciar Albertine: "Ora, esse amor nascido principalmente da necessidade de obstar que Albertine praticasse o mal, esse amor guardara em seu desenvolvimento o sinal de Origem." (PROUST, 2012, p. 38). No entanto, não oficializando a sua situação com a companheira, coloca a sua própria relação no desvio da norma de conduta. Desse modo, Bataille conclui: "A filha de Vinteuil personifica Marcel, e Vinteuil é a mãe de Marcel. A instalação em sua casa, enquanto seu pai ainda estava vivo, da amante da Srta. Vinteuil é paralela à de Albertine nos aposentos do narrador." (BATAILLE, 2015, p. 131). Segundo Bataille, a narração insistente dos tormentos que o Sr. Vinteuil sofreu em decorrência da má conduta da filha, em oposição ao silêncio em que o narrador relega as consequências da sua própria conduta com Albertine, traria à obra proustiana a ambivalência que caracteriza o Mal literário composto pelo filósofo: a impureza não pode prescindir do seu contrário, e a pureza só podendo ser conhecida, assim, por contraste: "O Mal parece apreensível, mas é na medida em que o bem é a sua chave. Se a intensidade luminosa do Bem não conferisse sua escuridão à noite do Mal, o Mal não teria mais o seu atrativo." (BATAILLE, 2015, p. 133).

É, portanto, da descrição do sofrimento, e não da satisfação, que se trata a relaçáo amorosa do narrador com Albertine - assim como as demais relaçóes amorosas de a Busca, pois, como enfatiza Bataille, é a provação da infelicidade, ou do Mal, que nos dá avidez pela felicidade, que em si mesma seria menos desejável do que tediosa. Disto decorre a necessidade do narrador de manter a incerteza, cada vez que ele hesita em apurar diretamente com Albertine as suas desconfianças, da mesma forma que a necessidade incontrolável, e masoquista, de se perder, e sofrer, em meio às incessantes hipóteses criadas imaginariamente:

De alguma forma, um aspecto dilacerante do amor se desprende de seus avatares múltiplos. Se o amor é por vezes rosa, o rosa se combina com o preto, sem o qual ele seria o signo do insípido. Sem o preto, o rosa teria o valor que atinge a sensibilidade? Sem a infelicidade a ela ligada como a sombra à luz, uma pronta indiferença responderia à felicidade. (BATAILLE, 2015, p. 133)

O desvio, portanto, é o movimento que permeia as relaçóes amorosas em a Busca. A incerteza acerca da homossexualidade da companheira leva o narrador por um caminho no qual desponta uma série de Albertines, cada nova figura surgindo para confirmar ou refazer a anterior, ou mesmo revelar uma nova faceta de uma personagem que se torna, assim, inapreensível: "cada um de nós não é um, pois contém numerosas pessoas que não têm todas o mesmo valor moral, e que, se tinha existido uma Albertine viciada, isso não impedia que houvesse outras" (PROUST, 2012, p. 148). Após a sua morte, essa série se intensifica: não havendo mais a possibilidade de uma confissão 
da própria Albertine, as informaçôes de terceiros sobre as suas tendências e relaçôes lésbicas sempre se contradizem, mantendo-a sob o véu da ambiguidade.

Albertine perpassa, assim, por uma série de personagens femininas, como Gilberte, Andrée e as demais raparigas do grupinho de Balbec, Srta. Vinteuil e sua amante, a atriz Léa, as primas de Bloch, que tramitam em torno do vício homossexual: “Em todo caso, as palavras de Gilberte, do 'ar duvidoso' de antes ao atual certificado de boa conduta, seguiam trajeto inverso ao das afirmações de Albertine, que acabara quase por confessar meias relaçóes com Gilberte.” (PROUST, 2013, p. 27). A dúvida se faz enigma, pois cada peça desse grande mosaico por se montar, que aparentemente se encaixa, desfaz uma revelação anterior. Desse modo, a trilha que o narrador segue na intenção da apreensão total do passado de Albertine, sendo móvel, se refaz indefinidamente: "Albertine surpreendeu-me com isso como já me surpreendera a respeito de Andrée, porque se, antes de conhecê-lo, eu já acreditava na perversão do grupinho, convencera-me depois da falsidade de minhas desconfianças [...] Mais tarde eu refizera o caminho em sentido contrário, voltando às convicções iniciais." (PROUST, 2013, p. 27). Os personagens de a Busca trazem, portanto, a ambivalência que caracteriza o Mal literário bataillano, usualmente pelo desvio da sexualidade que, náo acontecendo de forma irreversível, se desvia, oscila, retorna e estrutura os personagens de uma forma que os torna inapreensíveis e, portanto, inclassificáveis.

Assim se dá, por exemplo, a insuspeitada homossexualidade do outrora amigo próximo Robert de Saint-Loup, que, quando revelada em $A$ fugitiva, surpreende um atônito narrador pela inesperada mudança, denominada por ele como a inversão tardia do amigo. Essa mudança para o gênero dos invertidos, todavia, lhe permite, na tentativa de compreender o movimento de desvio que leva ao vício, poder traçar pelo caminho contrário uma observação sobre o caráter dessas pessoas - tipos como o tio de Saint-Loup, o Barão de Charlus, personagem emblematicamente homossexual da obra - e assim compor um provável perfil dos traços que compóem o ser que o narrador denomina invertido. Associado ao vício, portanto ao Mal, o que se verifica em decorrência de sua homossexualidade é uma degradação desses personagens, tanto fisicamente quanto moralmente. Se Saint-Loup não fora transformado fisicamente como o fora seu tio - "À medida que o Sr. de Charlus se tornava pesadão, Robert [...] ficara mais esguio, mais rápido, efeito contrário de um mesmo vício." (PROUST, 2013, p. 16) -, sua antiga ternura espontânea fora transformada em dissimulaçôes de ator que se perde em mentiras para esconder da esposa Gilberte, e de todos mais, a sua relação secreta com Morel, o seu "vício", elemento que se utiliza de um disfarce que finda por revelar aquilo que intenta ocultar: "Esse retorno, aliás, à elegância volátil dos Guermantes de bico pontiagudo, de olhos acerados era agora utilizado por 
seu novo vício que dela se servia para disfarçar. E quanto mais dela se servia, mais se assemelhava ao que Balzac chama de tia." (PROUST, 2013, p. 22).

Desse modo, se o personagem homossexual é o desvio da norma, ou melhor dizendo, se a homossexualidade desvia o personagem da norma, os personagens de sexualidade dúbia, que o narrador náo pode apreender totalmente, ou mesmo seguramente - as mulheres que sáo provavelmente ou ainda potencialmente "bissexuais" na obra - provocam, pelas oscilaçóes nas suposiçôes do narrador, a indefinição que os torna mais próximos do desvio do que da norma, consequentemente mais próximos do Mal do que do Bem: "Nenhuma dessas hipóteses era absurda, já que, em criaturas como a filha de Odette e as moças do grupinho, há tal diversidade, tal acúmulo de gostos alternados, ou mesmo simultâneos, que passam rapidamente da ligação com outra mulher ao grande amor por um homem, tornando-se dificílimo definir-lhes as preferências reais e dominantes." (PROUST, 2013, p. 28).

Para além de um mero desvio de conduta, o vício da homossexualidade torna-se a base do ser, perpassando toda a sua formação e compondo a sua personalidade, se evidenciando não apenas como um fator de desequilíbrio, que incita o ser ao desvio da norma, mas como o próprio desvio, uma vez que molda o caráter daquele que por ele é acometido, ao se expandir do campo da sexualidade para as demais facetas de sua personalidade. É por esse viés que o narrador identifica, na motivaçáo do amigo Robert em relação à guerra, não apenas um sentimento nacionalista ou um traço de sua hierarquia nobre, mas o fator preponderante da homossexualidade, que, no mundo às avessas que é o mundo da guerra, pode ser vivenciado inversamente, revelando na virilidade e coragem masculinas uma forma velada de entrega na qual a homossexualidade pode se manifestar na sua totalidade, invertendo também a sua ordem moral, pois o vício teria assim a aparente conduta da virtude: "para Saint-Loup a guerra foi mais o próprio ideal que ele imaginava seguir em seus desejos muito mais concretos, mas velados pela ideologia, um ideal partilhado com os seres que preferia, numa ordem de cavalaria puramente masculina, distante das mulheres, em que poderia expor sua vida para salvar seu ordenança, e morrer inspirando um amor fanático a seus homens." (PROUST, 2013, p. 72).

O movimento que leva da virtude ao vício não é, portanto, definitivo, nem tampouco irreversível. Se, como o narrador pôde identificar em SaintLoup, ele surge como um vício hereditário e tardio, degenerando os traços morais do amigo, este mesmo vício, tendo despontado na mais tenra idade, pode se dissipar, invertendo então a ordem do movimento em uma direção contrária, em que a degeneração dá lugar à elevação moral: "Assim, por compensação, enquanto certos jovens virtuosos, com a idade, se deixam levar por paixôes de que enfim tomaram consciência, adolescentes fáceis tornam-se 
homens de princípios contra os quais, os Charlus, acreditando em antigos relatos, mas tarde demais, esbarram desagradavelmente. Tudo é uma questão de cronologia." (PROUST, 2013, p. 63). Consequentemente, por se configurar pela ambivalência dos opostos, se o desvio sexual, na obra proustiana, é o vício que configura o Mal, ele só poderá se dar trazendo em si desde sempre o seu oposto, o Bem. Desse modo, Bataille afirma que "Só saímos do imbróglio onde o Mal se dissimula percebendo a ligação dos contrários, que não podem prescindir um do outro." (BATAILLE, 2015, p. 134), pois se é da provação da infelicidade que decorre o desejo de felicidade, sem a avidez pelo Bem o Mal nos proporia uma série de sensaçóes indiferentes.

Assim, Bataille ressalta, no sentido profundo atribuído à cena sádica e lésbica da enlutada Srta. Vinteuil com a amante - que o filósofo iguala à tragédia mais negra -, o jogo de contrastes no qual a impureza náo pode prescindir do seu contrário, pois se, para sugerir o desejo, a cor rosa precisa do seu contraste preto, sem uma sede inicial de pureza esse preto não seria suficientemente preto, e conclui que "Proust, ávido de gozo, deixava ao vício a cor odiosa do vício, sua condenaçáo pela virtude. Mas se foi virtuoso, não foi para atingir o prazer, e se atingiu o prazer, foi porque, antes, quis atingir a virtude." (BATAILLE, 2015, p. 133-134). De fato, as consideraçóes do narrador sobre a natureza do Mal contida na cena da profanação do retrato do morto a aproxima de um simbolismo rudimentar e ingênuo, pois táo completa era a aparência do Mal neste procedimento, que só em uma natureza sádica seria possível vê-lo realizado com tamanha perfeição, visto que ela própria não reconheceria estar praticando o Mal:

Mas, além das aparências, e pelo menos no princípio, o mal náo deve ter sido exclusivo no coração da srta. Vinteuil. Uma sádica como ela é um artista do mal, coisa que uma criatura inteiramente má não poderia ser, pois o mal não seria exterior a ela, antes lhe pareceria muito natural, não chegando mesmo a se distinguir de sua pessoa; e a virtude, a memória dos mortos, a ternura filial, como não lhes guardava culto, não sentiria nenhum prazer sacrílego em profaná-las. (PROUST, 2006a, p. 209)

Desse modo, não era o Mal que lhe dava a ideia do prazer, de algo aparentemente agradável, e sim o prazer que lhe parecia maligno, e identificando este com o Mal, nos momentos em que a ele se entregava, substituía, pelos maus pensamentos que o acompanhavam, o espaço natural de sua alma virtuosa por algo diabólico:

Os sádicos da espécie da srta.Vinteuil são uns seres tão puramente sentimentais, tấo naturalmente virtuosos que até o prazer sensual lhes parece uma coisa má, um privilégio dos maus. E quando se permitem entregar-se um momento 
a ele, é na pele dos maus que procuram entrar e fazer com que entre seu cúmplice, a fim de que possam ter por um instante a ilusão de se haverem evadido de sua alma escrupulosa e terna para o mundo inumano do prazer. (PROUST, 2006a, p. 209)

$\mathrm{O}$ jogo de contrastes que póe em oscilação a família Vinteuil se desenvolve, por conseguinte, pela oposição constante entre o Bem e o Mal, uma vez que, se a má conduta da filha conspurca socialmente a reputação do violinista, por consequência da relação desta com uma mulher mais velha e de má reputação em seu meio, o Sr.Vinteuil, no entanto, mesmo sendo um homem de princípios morais tão rígidos, por amor à filha, não só acolhe o vício homossexual na sua própria casa, como dele ainda extrai nuances de virtude:

A partir de certo ano, já não a encontrávamos sozinha, mas com uma amiga de mais idade, que tinha má fama na região e que um dia se instalou definitivamente em Montjouvain. Diziam: "Esse pobre Vinteuil deve estar mesmo muito cego de carinho para que não se dê conta do que falam e permitir que a filha leve para casa uma mulher daquelas, ele que se escandaliza com uma palavra imprópria. Diz ele que é uma mulher superior, um grande coração e que teria disposiçôes extraordinárias para a música se as tivesse cultivado. Pode estar certo de que não é de música que ela se ocupa com a sua filha." (PROUST, 2006a, p. 190-191)

Dessa forma, o desenvolvimento do Mal que o desvio homossexual acarreta na família é relativizado pelo Sr. Vinteuil - seja como uma forma de dele se redimir socialmente, seja porque "é com efeito notável como uma pessoa sempre provoca a admiração por suas qualidades de espírito e coração, por parte da família de qualquer outra pessoa com quem tenha relaçóes carnais.” (PROUST, 2006a, p. 191) - quando este vê naquela que contribui incisivamente para a sua degradação moral uma elevação de espírito que mescla a virtude de caráter com a virtude artística. Estabelece-se, então, pelos opostos do jogo do contraste entre o vício e a virtude, o movimento do Mal que retorna ao seu primeiro aspecto, o Bem, assegurando a afirmação de Bataille de que, nessa ligação de contrários, um elemento não pode prescindir do outro, estabelecendo-se também a relação direta entre o desenvolvimento do Mal e a elaboração da arte.

Pois o Sr. Vinteuil não sacrificou apenas a vida em decorrência dos dissabores que a ligação da filha e sua amante lhe trouxera; também renunciara para sempre aquilo que muito lhe valiam e constituíam a razão de ser da sua vida, as suas pobres composiçóes, toda a sua obra dos últimos anos que deixara de passar a limpo, sacrificando-a pela dedicação exclusiva à sua filha. Em uma nova aparente contradição de opostos, essas anotaçôes indecifráveis acabaram por ser decifradas, à força de paciência, de inteligência e de respeito, 
por aquela que convivera bastante com o músico para conhecer bem a sua maneira de trabalhar e lhe adivinhar as indicaçóes de orquestra, confirmando, assim, a virtude artística que lhe fora atribuída pelo morto:

A amiga da srta.Vinteuil sentia-se às vezes assaltada pelo importuno pensamento de ter talvez precipitado a morte de Vinteuil. Ao menos, passando anos a decifrar o quebra-cabeça deixado por Vinteuil, estabelecendo a leitura certa daqueles hieróglifos desconhecidos, teve a amiga da srta. Vinteuil o consolo de assegurar ao compositor, cujos derradeiros anos amargurara, uma glória imortal e compensadora. (PROUST, 2011, p. 167)

Assim, a cena de profanação traz em seu interior o seu aspecto contrário, pois a amante da Srta. Vinteuil aprendera com esta, ainda em vida do grande músico, o culto que a filha devotava ao pai e por causa do qual, num momento em que procederam contra as suas verdadeiras inclinações, as duas moças encontraram um prazer demente nas profanaçóes que foram narradas, colocando como condição mesma do sacrilégio a adoração da filha pelo pai. Disso, o narrador deduz uma recorrente série de contradiçóes dos sentimentos da Srta.Vinteuil pelo pai: inicialmente, uma tristeza, no momento em que profanava com a amiga a fotografia do pai, por ser tudo aquilo apenas doentio e não a verdadeira e alegre maldade que ela teria desejado, sendo essa ideia de simulação da maldade a única coisa que lhe estragava o prazer. Porém essa mesma ideia, assim como lhe havia estragado o prazer, minimizou-lhe o sofrimento se, por ventura, esta viera acudi-la mais tarde.

Desse modo, do jogo de opostos entre vício e virtude desabrocha a grande obra artística que deriva da oscilação intermitente entre o Bem e o Mal, pois da dedicação que Vinteuil consagrou à filha, vivendo e morrendo por ela sem receber a sua paga, e que culminou na sua suprema desgraça, nasce o seu reconhecimento póstumo, derivado este da aflição ainda mais amarga da Srta. Vinteuil, pois que sua perda foi somada ao remorso de haver matado aos poucos seu pai. Ao narrador de a Busca também o efeito da restauração da obra musical de Vinteuil lhe reparou o Mal trazido pela angústia incessante que lhe causava o ciúme inclemente que sentia por Albertine com o casal lésbico:

E eu, para quem, menos porém do que para Vinteuil talvez, ela fora também, era nessa noite mesma despertando novamente em mim o ciúme de Albertine, e haveria sobretudo de ser no futuro causa de tantos sofrimentos, graças a ela, em compensação, que pudera chegar a mim o estranho apelo que eu nunca mais deixaria de ouvir, como a promessa e a prova de que existia outra coisa, realizável pela arte sem dúvida, além do nada que eu encontrara em todos os prazeres e até no amor, e que se minha vida me parecia tão vã, ao menos não tinha ainda realizado tudo. (PROUST, 2011, p. 302) 
A música de Vinteuil retoma no narrador a lembrança da antiga resolução de escrever uma obra literária, que, constantemente procrastinada por ele, se lhe afigura como um objeto artístico inapreensível, assim como Albertine, como objeto amoroso, pois esta lhe permaneceu inacessível e desconhecida, uma vez que as coisas apenas ilusoriamente conhecidas são constantemente devolvidas à obscuridade do desconhecido, como afirma Bataille em "Digressão sobre a poesia e Marcel Proust", de $A$ experiência interior, texto no qual o filósofo reforça a relaçáo de causa e efeito entre a tentativa de limitação, aprisionamento e possessão do objeto de desejo e o fim do amor, na conduta do narrador com Albertine: "A qualquer preço, no entanto, ele queria fechá-la, possuí-la, 'conhecê-la', e é muito pouco dizer que queria: a tal ponto o desejo era forte, excedente, que se tornou a garantia da perda." (BATAILLE, 2016, p. 179). Bataille afirma ainda que o conhecido pertence táo pouco aos momentos de felicidade, que a respeito de uma frase do septeto de Vinteuil o narrador diz:

Depois elas se afastaram, com exceção de uma que vi tornar a passar umas cinco ou seis vezes, sem que eu lhe pudesse distinguir o rosto, mas tão carinhosa, tão diferente [...] do que uma mulher alguma vez me tivesse feito desejar que aquela frase, que me oferecia com voz tão amorável uma felicidade que realmente valeria a pena obter, foi talvez - invisível criatura cuja linguagem eu não conhecia mas compreendia tão bem - a única Desconhecida que jamais me tenha sido dado encontrar. (PROUST, 2011, p. 299)

Assim, afirma ainda Bataille, que, quando satisfeito, o desejo morria, pois se ele cessava de ser o desconhecido, o narrador cessava de estar sedento por conhecer, cessava de amar. Aquilo que uma mulher tinha de desejável era a parte dela de desconhecido, mas sempre o conhecimento matava o desejo, destruindo o desconhecido: "O amor voltava com a suspeita de uma mentira, pela qual Albertine se esquivava ao conhecimento, à vontade de posse." (BATAILLE, 2016, p. 179). A mentira se firma, pois, como um elemento constituinte do jogo de opostos que caracteriza o Mal bataillano, pois que traz em sua essência o seu oposto, a verdade, que se presentifica por sua ausência, pondo em contraste, desse modo, elementos contrários; é, ainda, atribuída pelo narrador como ato intrínseco da homossexualidade: "Raça sobre a qual pesa uma maldição e que tem de viver em mentira e perjúrio, já que sabe que se tem por punível e inconveniente, por inconfessável, o seu desejo, o que constitui para cada criatura a máxima doçura de viver" (PROUST, 2008, p. 31). E, como elemento inerente à condição homossexual, a mentira se estabelece como componente intrínseco à dubiedade que fomenta o ciúme e póe a relação do casal em uma zona indefinida entre o real e o imaginário: "Quanto a Albertine, sentia que jamais apreenderia coisa alguma, que entre 
a multiplicidade entremesclada dos pormenores reais e dos fatos mentirosos, jamais conseguiria esclarecer-me." (PROUST, 2008, p. 167).

A narrativa de a Busca se desenvolve, assim, como um desdobramento desse jogo de opostos - tanto na relaçáo amorosa do narrador com Albertine, como naquele que Bataille identifica como a estrutura do Mal literário, pois se, por repúdio ao desvio homossexual e à mentira a ele inerente, o narrador intenta manter junto de si Albertine, ele finda por criar uma narrativa que ao mesmo tempo que constrói, destrói aquela que ela não apreende. Toda a ação (imaginária) de $A$ prisioneira, por exemplo, que consiste em evitar a aproximação de Albertine de outras mulheres, deixa de fora a ação (real) que a sua tia, a Sra. Bontemps, urdia, à revelia do narrador, para uma aproximação da sobrinha com Octave, no intuito de um bom casamento que a retirasse da relação incerta, e portanto desviada, que ela mantinha com o narrador. Os ardis que o narrador se utiliza para desviar a companheira do vício, desse modo, somente a afastavam do caminho da virtude, desviando-a, pela mentira, para a mentira que ele intentava estancar.

Ao mesmo tempo, os fatos que motivam o sentimento do narrador se revelam igualmente mentirosos, pois Albertine nunca convivera com a Srta.Vinteuil e sua amante; portanto, o narrador nunca a teria tomado em cativeiro se não fosse conduzido pelo estratagema da mentira, estratagema que, entretanto, ele se utiliza para entrar no jogo ardiloso da companheira: "Sob o império do ciúme, aquele que acusava Jaurès se faz cínico. A ingênua honestidade inicial não é por isso menos digna de atenção. A Busca acumula os testemunhos de Marcel, a quem o ciúme levava a manobras tortuosas. Mas essas condutas táo opostas, que de início nos pareciam excluir-se mutuamente, reúnem-se num jogo.” (BATAILLE, 2015, p. 128-9).

O nome desse jogo se chama Em busca do tempo perdido, a obra que, no decorrer da narração do inseguro e ciumento narrador sobre as múltiplas possibilidades de desvio de sua amada Albertine pelo caminho do Mal, culmina por imergir toda a sua narração na base desse caminho, pois que no intuito de combater o vício homossexual e a mentira que lhe é indissociável, finda por traçar a sua narração pelo caminho dúbio que ele repudia, pois que intenta a virtude pelo caminho do vício, ao usar a mentira na intenção de chegar ao seu elemento oposto, a verdade: "Na base de uma virtude está o poder que temos de quebrar a sua cadeia. [...] Se há moral autêntica, sua existência está sempre em jogo. $\mathrm{O}$ verdadeiro ódio pela mentira admite, não sem um horror superado, o risco corrido numa determinada mentira." (BATAILLE, 2015, p. 130).

A partir do ciúme, decorrente da suspeita da homossexualidade da companheira, desvio inerente a outros personagens da obra, o narrador se perde em divagações que levam a sua narração pelo caminho da indefinição e 
da ambiguidade, caminho que se faz ainda pelo jogo da mentira, ambivalência que estrutura a sua narração na teia de contrastes que se faz pelos elementos opostos em que a satisfação, a virtude e o Bem só podem se dar a partir dos seus contrários, a insatisfação, o vício e o Mal, trazendo assim toda a narrativa para o mundo do desvio, do avesso, da ausência, mundo ambíguo que é a base da linguagem que constitui a escrita literária. Movimento oscilante que se fará obra por outro jogo de opostos, quando, ao final da narrativa, o narrador tocará no tempo puro da escrita, dando início à escrita de sua obra, que o levará como personagem ao caminho onde a escrita se iniciará, e de onde uma vez mais o vício dos personagens o levará, do Bem ao Mal, do Mal ao Bem, à escrita que se faz pelo caminho do desvio.

\section{Referências Bibliográficas}

BATAILLE, Georges. A literatura e o mal. Tradução de Fernando Scheibe. Belo Horizonte: Autêntica Editora, 2015.

BATAILLE, Georges. A experiência interior: seguida de Método de Meditação e Postscriptum 1953. Tradução de Fernando Scheibe. Belo Horizonte: Autêntica Editora, 2016.

PROUST, Marcel. No caminho de Swann. Tradução de Mario Quintana. 3a. ed. São Paulo: Globo, 2006a.

PROUST, Marcel. À sombra das raparigas em flor. Tradução de Mario Quintana. 3 a. ed. São Paulo: Globo, 2006b.

PROUST, Marcel. O caminho de Guermantes. Tradução de Mario Quintana. 3a. ed. São Paulo: Globo, 2007.

PROUST, Marcel. Sodoma e Gomorra. Tradução de Mario Quintana. 3a. ed. São Paulo: Globo, 2008.

PROUST, Marcel. A prisioneira. Tradução de Manuel Bandeira e Lourdes Sousa de Alencar. 13a. ed. Sáo Paulo: Globo, 2011.

PROUST, Marcel. A fugitiva. Tradução de Carlos Drummond de Andrade. São Paulo: Globo, 2012.

PROUST, Marcel. O tempo redescoberto. Tradução de Lúcia Miguel Pereira. 3a. ed. São Paulo: Globo, 2013. 
Francisco Renato de Souza. Doutor em Teoria Literária pela Universidade Federal do Rio de Janeiro (UFRJ). No momento, prepara uma pesquisa de Pós-doutorado sobre a obra de Marcel Proust, Em busca do tempo perdido. Atua nas áreas da literatura brasileira contemporânea, da teoria literária e se especializa ultimamente na obra de Marcel Proust. E-mail: paconato_@hotmail.com 